\title{
Acute Myeloid Leukemia Arising from Previous Myelodysplastic Syndrome
}

National Cancer Institute

\section{Source}

National Cancer Institute. Acute Myeloid Leukemia Arising from Previous Myelodysplastic

Syndrome. NCl Thesaurus. Code C4037.

An acute myeloid leukemia developing in patients with a prior history of myelodysplastic syndrome. 